This item was submitted to Loughborough's Research Repository by the author.

Items in Figshare are protected by copyright, with all rights reserved, unless otherwise indicated.

\title{
Analysis of impact induced damage in composites for wind turbine blades
}

PLEASE CITE THE PUBLISHED VERSION

http://dx.doi.org/10.1109/PGSRET.2015.7312210

PUBLISHER

(c) IEEE

VERSION

AM (Accepted Manuscript)

LICENCE

CC BY-NC-ND 4.0

REPOSITORY RECORD

Ullah, Himayat, and Vadim V. Silberschmidt. 2019. "Analysis of Impact Induced Damage in Composites for Wind Turbine Blades”. figshare. https://hdl.handle.net/2134/21261. 


\section{Analysis of impact induced damage in composites for wind turbine blades}

\author{
Himayat Ullah* \\ CESAT, Islamabad, Pakistan, email: uhimayat@gmail.com
}

\author{
Vadim V. Silberschmidt \\ Wolfson School of Mechanical and Manufacturing \\ Engineering, Loughborough University, Leicestershire, \\ LE11 3TU, UK
}

\begin{abstract}
Glass fabric-reinforced polymer (GFRP) composites used in wind turbine blades are usually exposed to large-deflection bending impacts caused by wind storms, heavy rainfall, water splashes and hailstones in the offshore; and sand and dust impingement in the desert environments. Such loadings can cause deterioration of structural integrity and load-bearing capacity of the blade structure due to induced damage in the form of matrix cracking, delamination and fibre fracture. These types of damage mechanisms become more detrimental and pose a threat to the fatigue life of the turbine blades.

In this work, first the load-bearing and energy absorbing capability of woven GFRP laminates is investigated under impact loading. Experimental tests are conducted to characterise the behaviour of GFRP composites under large-deflection dynamic bending in Izod type impact tests using Resil impactor. Impact tests are performed at various energy levels to determine the ultimate fracture toughness of the laminates. In these tests, the material demonstrated interply delamination damage due to weaker matrix at low energy levels. At higher impact energies, apart from delamination, the material also exhibited permanent deflection instead of catastrophic fabric fracture. The latter was due to the visco-elasto-plastic nature of the glass fibres apart from the thermoplastic matrix. The deformation behaviour and delamination damage ensued by dynamic loading is also studied by developing three-dimensional finite element (FE) model in Abaqus/Explicit commercial package. In FE model, multiple layers of bilinear cohesive-zone elements are defined at the damage locations. Stress-based criteria and fracture-mechanics techniques are used to assess damage initiation and its progression, respectively. Numerical results gave good correlation when compared to the dynamic response observed in experiments. The methodology developed here can be employed in damage tolerant design of wind turbine composite blades subjected to similar impact loading conditions.
\end{abstract}

Keywords-GFRP, Wind turbin; finite-element model; permanent deflection; damage tolerant

\section{INTRODUCTION}

The application of woven composites is ever increasing in structures demanding low weight, high specific strength and stiffness and better resistance to impact damage particularly delamination [1]. Apart from aerospace, automotive and civil structural elements, woven composites are being used in renewable energy applications such tidal and wind turbine blades. The wind turbine blades are exposed to both extreme one-off loads and severe fatigue loads during their 20-25 year required lifetimes due to harsh winds and heavy rainfall [2]. Further, the blades can also be subjected to hail storm impacts and sea water splashing in the off-shore environment [3] and sand and stone impacts in the desert environment. These requirements dictate the use of composite materials such as glass fabric-reinforced polymer (GFRP) laminates to provide the required stiffness, strength and fatigue life, as well as resistance to impact and corrosion, while minimizing the weight of the blade and allowing its geometric shape to provide the required aerodynamic performance. However, the severe types of loads and impacts result in large deflection bending of the blades; generating high local stresses and deformations ensuing complex damage modes in the blades because of heterogeneous and anisotropic behaviour of composites. Among these loads, impact loading causes more damage in composite structures than their metallic counterparts. The damage mechanisms typically caused by low velocity impacts in laminates are matrix cracking, fibre fracture and delamination at resin-rich interfaces within the composite structure [4]. Impact damage especially delamination cause a substantial reduction in the material's compressive strength and stiffness. Further, in turbine blades, the spar caps are joined with the skins through thick adhesive layers, which has low interlaminar strength and more susceptible to delamination causing separation of spars and skins leading to catastrophic failure of the blade [5]. These internal damage mechanisms that are usually barely visible degrade the load-carrying capability of the wind turbine blades. Therefore, it is important to study the energy absorbing capability and delamination damage of woven composites for their effective and damage-tolerant designs as it is uneconomical and difficult to replace damaged blades in service, especially if the turbines are installed in offshore environment [6].

The low-velocity impact behaviour of fabric-reinforced composites has been extensively studied in the literature employing experimental studies, analytical methods and numerical simulations e.g. in [7-10] among others. However, majority of these studies are related to the dynamic behaviour of composites tested with instrumented drop-weight impact towers, which usually cause localised deformation and damage such as penetration and perforation in composites. A largedeflection dynamic bending behaviour of laminated composites experienced by wind turbine blades during service is rarely studied. Investigation of large-deflection bending behaviour of 
GFRP composites caused by low velocity impacts has received little attention to date. In this regard few studies can be found (e.g. Silberschmidt et al. [11] and Casas-Rodriguez et al. [12]) where an instrumented impactor was used to study damage in adhesively bonded CFRP joints under impact fatigue; still the loading mode was tensile there. To describe the impact and predict the impact induced damage mechanisms in composites, the framework of high fidelity numerical models based on the finite element method has proved to be a more reliable, costand time-effective tool than analytical formulations, experimental tests or microstructural studies. As employed in this study, finite-element analyses can provide the detailed information on the spatial and temporal distribution of delamination damage during impact; which is too difficult to obtain experimentally and analytically.

In this work, a large-deflection bending behaviour of woven fabric GFRP laminates subjected to low velocity impact as experienced by wind turbine blade is studied. Impact tests were conducted by using a pendulum type impact tester at various energy levels to assess the material's energy absorbing capability and strength. Three-dimensional (3D) finite-element model was developed in Abaqus/Explicit for the damaged specimen by employing cohesive zone elements (CZEs) at the delamination locations between the plies. Mixed-mode bilinear traction-separation cohesive laws governed the onset as well as propagation of damage. The obtained modelling results have good agreement with experimental data.

\section{EXPERIMENTAL METHODS}

Fabric-reinforced GFRP specimens were prepared from woven fabrics made of glass fibres reinforced thermoplastic polyurethane (TPU) polymer matrix. The specimen was manufactured from $0^{\circ} / 90^{\circ}$ prepregs in the form of four plies designated as $\left[0^{\circ}, 90^{\circ}\right]_{2 \mathrm{~s}}$, where $0^{\circ}$ and $90^{\circ}$ represent tows in the warp and weft directions, respectively. The specimen had a $2 / 2$ twill balanced weaving pattern with a fibre volume fraction of $45 \%$. Un-notched rectangular specimens of $40 \mathrm{~mm}$ length, 25 $\mathrm{mm}$ width and $1.0 \mathrm{~mm}$ thickness were prepared. Low velocity impact tests were conducted on an instrumented pendulum-

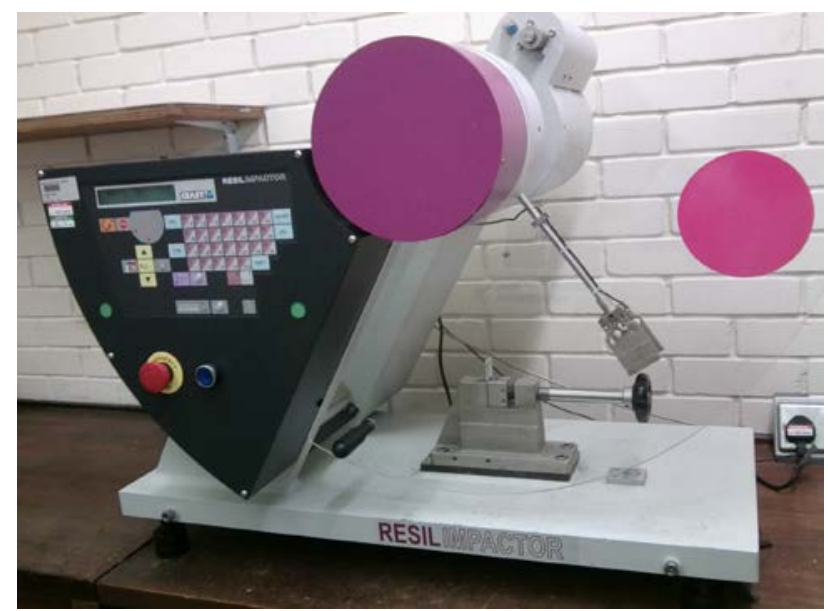

Fig. 1. Resil impact test set-up with GFRP specimen type CEAST Resil impactor according to ISO 180 standard. In these tests, the bottom of the specimen was fixed in the machine vice as a cantilever beam as shown in Fig. 1. The upper $30 \mathrm{~mm}$ of the specimen was hit by the striker of the pendulum hammer with a controlled level of energy during impact. The line of impact of the hammer's striking nose was kept at $22 \mathrm{~mm}$ above the fixed support according to the standard. The magnitude of initial impact energy and velocity was varied by changing the initial angle of the hammer. Impact tests were performed on GFRP specimens at energy levels of $0.1 \mathrm{~J}-1.1 \mathrm{~J}$, to determine the impact energy absorption of the specimens. During testing, the hammer was released from its initial angular position. At the instant of impact of the hammer with the laminate, the piezoelectric sensor attached to the striker of the hammer creates a change in electrical resistance, which is recorded by the data - acquisition system connected to the Resil impactor test setup. The signal is registered with a pre-defined sampling frequency of $833 \mathrm{kHz}$, with up to 8000 data points recorded per test. A $1 \mathrm{kHz}$ filter was used to decrease the noise observed in the test data.

Typical records of force $v s$. time for GFRP specimens tested at energy levels of $0.1 \mathrm{~J}-1.1 \mathrm{~J}$ are presented in Fig. 2. From these plots, it is clear that the slope and the peak load of the force-time curves increased with increase in the impact energy. At low energy levels, a linear increase of force with time is observed at the start of loading, representing a purely elastic undamaged response of the specimen. The loading and unloading portions of the force-time curves have a nearly symmetric parabolic shape up to $0.3 \mathrm{~J}$ (Fig. 2), indicating that very little damage has occurred. As the impact energy increased, a Hertzian failure can be observed at the start of the impact events beyond $0.8 \mathrm{~J}$. The specimens tested at energies between $0.8 \mathrm{~J}-1.1 \mathrm{~J}$ also exhibited a permanent yielding after testing, which might be due to the visco-elasto-plastic nature of the glass fibres apart from the TPU matrix. In dynamic tests of GFRP specimens, the contact duration increased with increase in the impact energy (see Fig. 2). Such a response indicates that

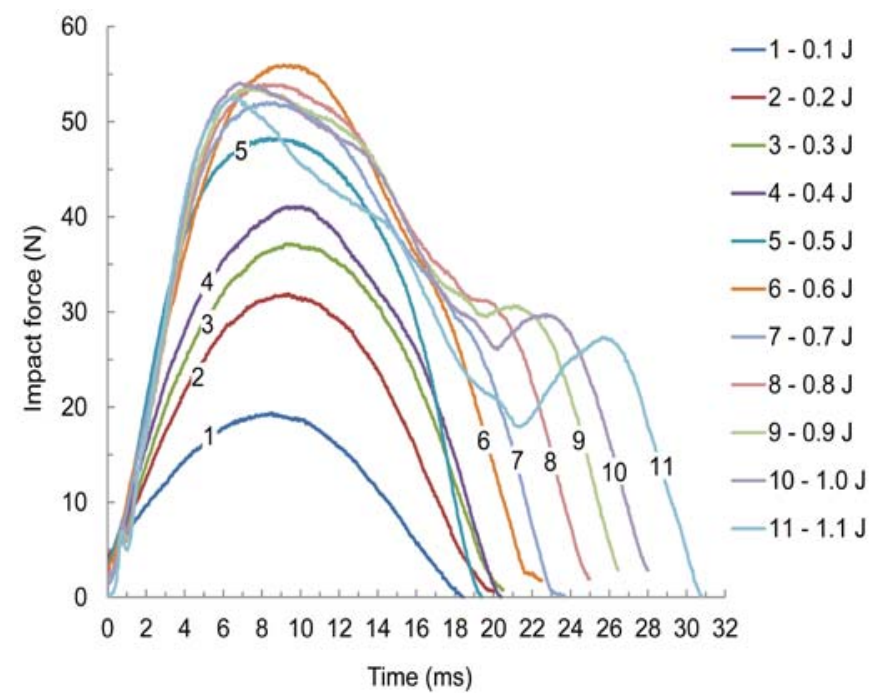

Fig. 2. Experimental force vs. time response of twill 2/2 GFRP laminates at various impact energies 


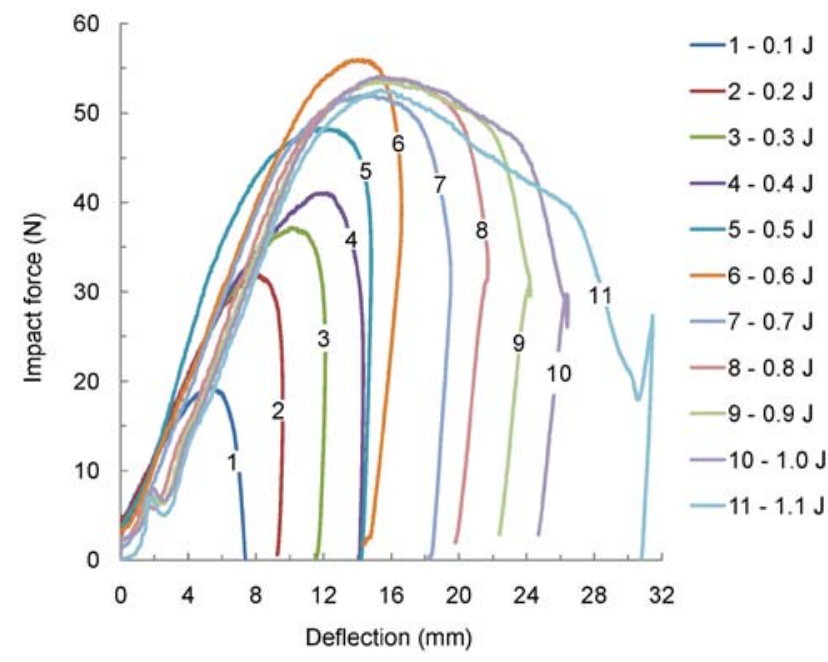

Fig. 3. Experimental force vs. deflection response of twill $2 / 2$ GFRP laminates at various impact energies

the material's behaviour is strain rate-dependent under dynamic loading even in on-axis GFRP composites.

Force versus deflection response of GFRP specimens at various energy levels is shown in Fig. 3. The slope of forcedeflection curves represents the contact stiffness, while the enclosed area under the curves gives the absorbed energy. The descending sections of the curves, where both the load and deflection decrease, represent rebounding of the hammer. Clearly, the area under the curves increased with impact energy indicating an increase in the energy absorbed by GFRP laminates. In the GFRP materials, the TPU matrix material is highly compliant and usually absorbs more energy without causing any appreciable damage. As evident from Fig. 3, at the higher energy levels, with the increase of load, the specimens yielded, implying the onset of plastic deformation represented by the plateau at the top of the curves. Thus, the specimens underwent large deformation during loading; and subsequently, a snap-back during the rebound (with the striker slipping past the specimen), represented by the depths and kinks in Figs. 2 and 3. These drops corresponded to the loss of contact between the hammer and the specimen for a short while during slippage. Further, GFRP composites did not demonstrate a catastrophic brittle fracture but rather deformed permanently at higher impact energies. This means that although GFRP composites are less strong but they sustain higher impact energy before their collapse. In these low velocity impact tests, the thin GFRP laminates failed at low energy levels. The reason is that in the Izod-type impact tests, where only one side of the specimen is clamped and the rest are free, resulting in lower in-plane membrane stresses and flexural rigidity. Also, the specimen's thickness is small in comparison with other dimensions of the specimen resulting in lower flexural rigidity. Obviously, flexural rigidity of the composite specimens depends on material's stiffness, their size and boundary conditions. Hence, the decrease in flexural rigidity and stress-stiffening effect in the thin cantilevered specimens required lower energies for their deformation and damage initiation, propagation and ultimate failure.

\section{NUMERICAL ANALYSIS}

\section{A. Finite-element model}

Finite-element model was built in commercial FE software Abaqus/Explicit to predict the low velocity impact behaviour of tested composite specimen with consideration of the resulting delamination damage. In the FE model of damaged GFRP specimen of $40 \mathrm{~mm}$ length, $25 \mathrm{~mm}$ width and $1 \mathrm{~mm}$ thickness tested at $0.4 \mathrm{~J}$ impact energy, cohesive-zone elements were described at the resin-rich interfaces between the specimen's plies. As there are three resin interfaces between the specimen's plies, thus three longitudinal cohesive layers were defined in the model to analyse multiple delamination scenarios. The cohesive layers in the FE model are described as: FCL - front cohesive layer in front of the specimen's neutral plane (NP); MCL - mid cohesive layer coinciding with the NP; and BCL back cohesive layer to the back of the NP. All composite plies were assigned elastic flexural properties listed in Table 1. The hammer made of steel was assigned the Young's modulus of $200 \mathrm{GPa}$, Poisson's ratio 0.3 and density $8100 \mathrm{~kg} / \mathrm{m}^{3}$.

The modelled geometry consisting of hammer and specimen is shown in Fig. 4 along with mesh and boundary conditions. The hammer was discretised with 4-noded linear tetrahedron C3D4 elements, whereas each ply of the specimen was meshed with a single 8-noded linear brick C3D8R element through its thickness, using a mapped meshing technique. Elastic as well as damage properties of interlaminar cohesive layers presented in Table 1 can be found in the previous work of the authors $[1,13]$. The interaction between the hammer and the specimen was simulated by using surface-to-surface kinematic contact algorithm with finite sliding in Abaqus/Explicit, which is based on penalty contact method. The impactor's striking surface and laminate's surfaces referred as $S_{1}$ and $S_{2}$ in Figs. $4 b$ and $4 c$, respectively, were designated as target and contact surfaces. A node at the pivot point of the hammer along the axis of rotation was defined and then tied with the hammer's cylindrical pivot surface using tie constraints. All degrees of freedom of the pivot node were fixed except rotation about $\mathrm{z}$-axis to simulate the hammer's centre of rotation as shown in Fig. 4a. In the FE model, the initial position of the hammer was described closer to the specimen to avoid the computational cost of bringing the hammer from its inclined position in tests. An angular velocity of $4.72 \mathrm{rad} / \mathrm{s}$ was assigned to the whole hammer, corresponding to the impact energy of $0.4 \mathrm{~J}$. All the nodes of the specimen's bottom edge were fixed in all directions to simulate its clamping conditions in experimental tests.

\section{B. Delamination modelling}

The interlaminar delamination damage in FE model was simulated using cohesive-zone elements (CZEs), which have the capability to simulate both the initiation and progression of delamination in a single model $[13,14]$. The cohesive behaviour is based on the assumption that failure of elements is governed by progressive degradation of the material stiffness, which is driven by a damage process. Interlaminar damage modes in composites initiate and progress under the combined effect of normal and shear stresses. The interlaminar damage 


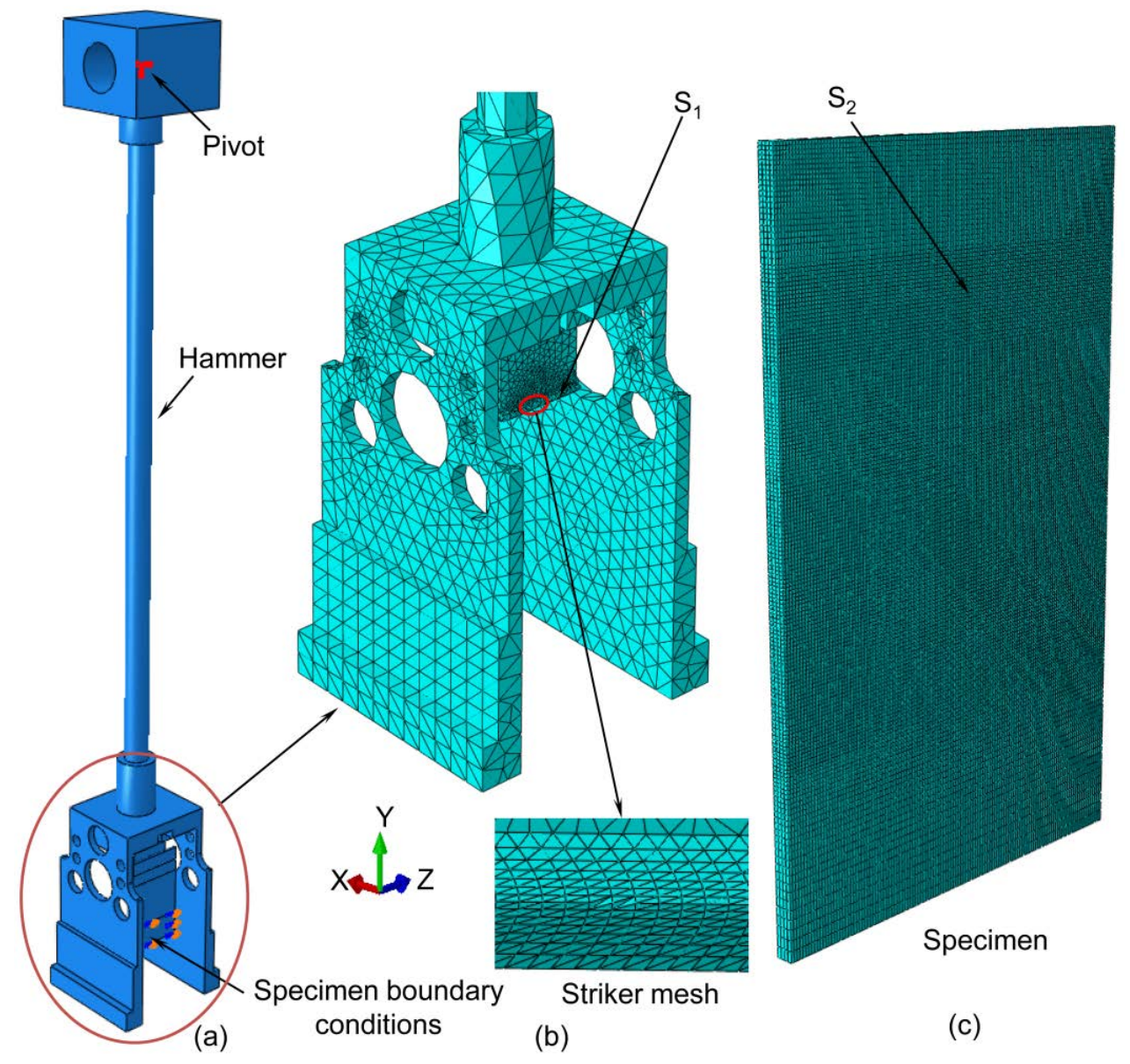

Fig. 4. Impact-test FE model: (a) 3D geometry with boundary conditions; (b) hammer-specimen contact interaction; (c) mesh of specimen in FE model (specimen is shown larger)

initiation was predicted with nominal quadratic stress criterion, which has proven to be suitable for onset of delamination in composites. The criterion for mixed-mode propagation of damage is generally defined in terms of the energy release rates and fracture toughness of the material in various modes. In this study, damage propagation was predicted using the criterion proposed by Benzeggah and Kenane [15]:

$$
G_{c}=G_{\mathrm{Ic}}+\left(G_{\mathrm{II} c}-G_{\mathrm{Ic}}\right)\left[\frac{G_{\mathrm{S}}}{G_{\mathrm{T}}}\right]^{\eta}
$$

where $G_{\mathrm{T}}$ is the work by the interface tractions; $G_{\mathrm{S}} / G_{\mathrm{T}}$ is the fraction of cohesive energy dissipated by shear tractions; $G_{\mathrm{S}}$ is the work done by the shear components of interface tractions; $G_{\text {IC }}$ and $G_{\text {IIc }}$ are fracture toughness of the material in modes I and II, respectively, and $\eta$ is the material constant. The damage-initiation and fracture-toughness parameters presented in Table 1 were used in the FE Model. The interface element stiffness was based on the approach by Daudeville et al. [16], which defines the interface stiffness as $K=E_{33} / t_{i}$, where $E_{33}$ is the laminate's through-thickness elastic modulus and $t_{i}$ is the thickness of the resin-rich interface between plies. This relation gives the interface stiffness of $8 \times 10^{6} \mathrm{~N} / \mathrm{mm}^{3}$, used in this study, taking $10 \mu \mathrm{m}$ thick interface. In order to capture the damage growth properly, the mesh must be sufficiently fine within the cohesive zone. However, excessive mesh refinement of interface elements results in higher computational cost. Thus, the number of elements $N_{e}$ in the cohesive-zone is optimised according to $N_{e}=l_{c z} / l_{e}$, from [14], where $l_{c z}$ is the length of cohesive-zone and $l_{e}$ is the element length along the crack propagation path. Cohesive elements of size $0.3 \mathrm{~mm}$ $\mathrm{x} 0.3 \mathrm{~mm}$ with thickness of $10 \mu \mathrm{m}$ were defined for computationally effective simulation of damage in our numerical model. As compared to implicit solver, an explicit solver along with automatic stabilisation resulted in a better convergence of the analysis involving nonlinearities such as stiffness degradation and material softening during damage progression.

Table 1.Material properties of GFRP considered in FE model

\begin{tabular}{|l|l|l|c|}
\hline \multicolumn{2}{|c|}{ Elastic properties } & \multicolumn{1}{|c|}{ Inter-ply strength and toughness } \\
\hline$E_{11}=E_{22}(\mathrm{GPa})$ & 21.5 & $\sigma_{\mathrm{I0}}(\mathrm{MPa})$ & 27.3 \\
$E_{33}(\mathrm{GPa})$ & 8.0 & $\sigma_{\mathrm{II}}(\mathrm{MPa})$ & 10.6 \\
$G_{12}(\mathrm{GPa})$ & 3.1 & $G_{\mathrm{Ic}}\left(\mathrm{J} / \mathrm{m}^{2}\right)$ & 1210 \\
$G_{13}=G_{23}(\mathrm{GPa})$ & 3.6 & $G_{\text {IIc }}\left(\mathrm{J} / \mathrm{m}^{2}\right)$ & 4550 \\
$v_{12}$ & 0.11 & & \\
$v_{13}=v_{23}$ & 0.3 & & \\
\hline
\end{tabular}




\section{RESUlTS AND DisCUSSION}

Experimental and numerical simulation results for the low velocity impact behaviour of woven GFRP specimens are presented in this section. The load-time response calculated with numerical model is compared with the respective experimental curve of damaged specimen in Fig. 5. The load drops in the force-time history obtained from the test designated as $\mathrm{F}_{\mathrm{di}}$-Exp represent the delamination initiation at low incident energy with an associated reduction in the material stiffness. It can be observed that a reasonable agreement is obtained between simulation and experiment for the global response of the damaged specimen. However, the numerical damage threshold $\mathrm{F}_{\mathrm{di}}-\mathrm{FE}$, at which the damage initiation occurred, is clearly under-predicted. This shortcoming of the model may be due to the meso-level description of the plies in FE model. As in experimental tests, the woven composites absorb more energy due to the compliant resin-rich regions between the tows and fibre trellising of tows, and, thus, offer more resistance to damage initiation and growth, which were not elaborated the FE model. Also, the visco-elasto- plastic material behaviour was not defined for the GFRP specimen in the FE model, which might be the cause of this discrepancy. Further, the contact duration is overestimated in the simulation, which might be due to lower values of stiffness defined for cohesive elements.

Fig. 6 shows the evolution of predicted damage areas such as delamination at three interfaces - FCL, MCL and BCL - in FE analysis at two different time intervals: at $1.5 \mathrm{~ms}$ (near $\mathrm{F}_{\mathrm{di}}-\mathrm{FE}$ in Fig. 5) and at $11 \mathrm{~ms}$ (near peak load in Fig. 5). In this analysis, delamination initiated first at the area of hammer impact and then at the clamping location of the cantilevered GFRP specimen, i.e. the edge of the vice. The sharp corners of the hammer's striker developed stress concentration causing more damage in the specimen below the corners. Beyond the time corresponding to $\mathrm{F}_{\mathrm{di}}-\mathrm{FE}$, a large and quick increase in the

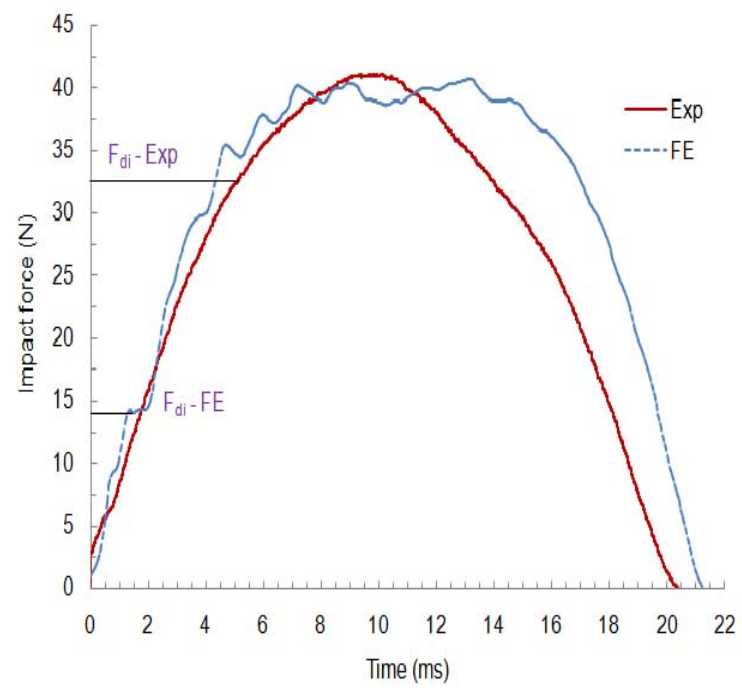

Fig. 5. Experimental and numerical force-time diagrams for GFRP laminates at impact energy of $0.4 \mathrm{~J}$ showing response of damaged specimen (a)
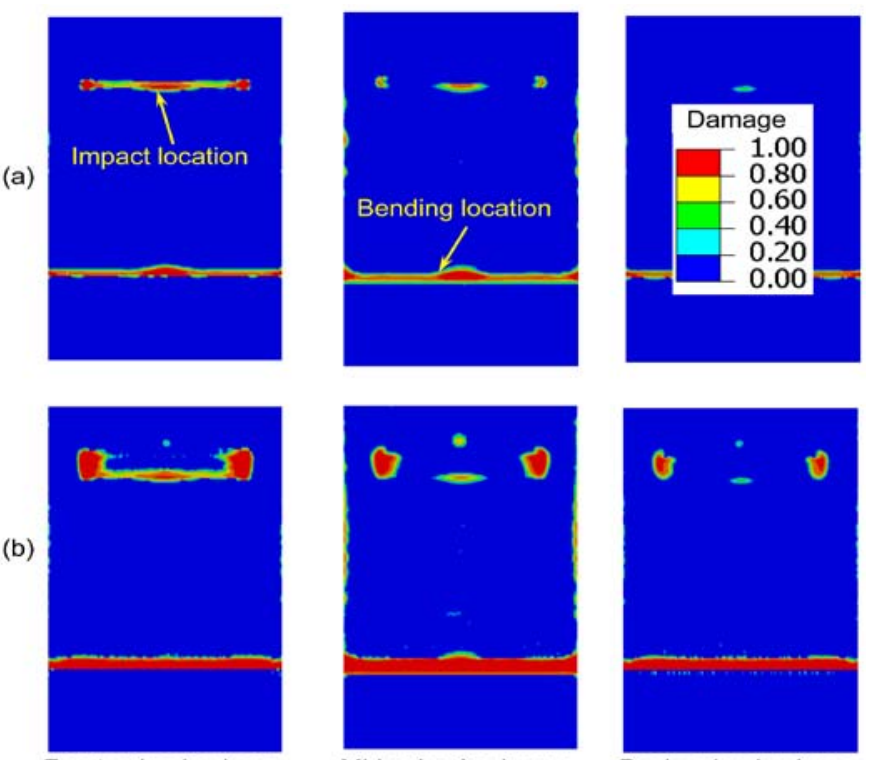

Front cohesive layer (FCL)

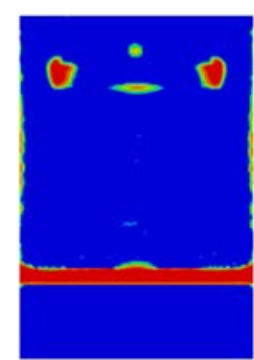

Mid cohesive layer (MCL)

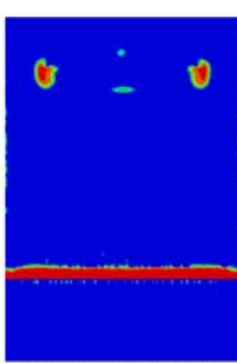

Back cohesive layer $(\mathrm{BCL})$

Fig. 6. Evolution of interlaminar delamination in FE model at impact energy of $0.4 \mathrm{~J}$ at (a) $1.5 \mathrm{~ms}$ and (b) $11 \mathrm{~ms}$

delamination areas was observed simultaneously in all the cohesive interfaces. As it is evident from the figure, a larger area of delamination occurred at the front interface layer FCL at the impact location, whereas the bending location of mid interface layer (MCL) was more damaged due to higher through-thickness shear stress at the neutral plane of the specimen. Similarly, in bending, the upper (front) and lower (back) plies subjected to tension and compression, respectively. Thus, the maximum bending stresses were responsible for damage progression at FCL and BCL of the specimen, especially at the clamping location. Unlike the bottom-to-top type of damage pattern in specimens subjected to drop weight impact tests, a front-to-back (top-to-bottom) type of damage pattern was observed in the Izod type impact simulations.

\section{CONCLUSIONS}

This paper presented a study on the dynamic behaviour of woven GFRP specimens used in wind turbine blades subjected to low velocity impacts employing experimental tests and numerical simulation. Impact tests were performed to investigate the material's dynamic behaviour till its ultimate failure. The material exhibited permanent deformation instead of brittle fabric fracture at higher impact energy levels, which might be due to the visco-elasto-plasticity of GFRP laminates. An explicit finite element analysis of GFRP laminates was carried out to simulate inter-ply delamination damage in woven composites at the impact and specimen bending locations. Numerical model was built to study the onset and growth of interlaminar damage modes under mixed-mode impact bending by inserting multiple layers of CZEs in the FE model. The experimental result for contact-force history was compared with respective numerical prediction, which gave a reasonable agreement. The numerical model demonstrated its potential to replicate the damage sequence and pattern in GFRP specimen. The FE model enhanced the understanding of the complex 
damage phenomena that occurred at various intervals of impact bending, which was difficult to obtain with experimental observations. It was also found that the observed damage pattern in the specimen at the impact location was from its front to the back in this study, unlike the bottom-to-top conical damage formation in drop weight tests. In future, an explicit representation of fibre tows apart from the visco-elasto-plastic behaviour of the material will be incorporated in the FE model.

\section{REFERENCES}

[1] Ullah H, Harland AR, Silberschmidt VV. Damage and fracture in carbon fabric reinforced composites under impact bending. Composite Structures. 2013;101(0):144-56.

[2] P.W.Harper;, S.R.Hallett. Advanced numerical modelling techniques for the structural design of composite tidal turbine blades. Ocean Engineering. 2015;96:272-83.

[3] Keegan. MH, Nash. DH, Stack MM. Modelling rain drop impact of offshore wind turbine blades. Proceedings of TurboExpo. June 11-15, 2012, Copenhagen, Denmark.

[4] Ullah H, Harland AR, Silberschmidt VV. Evolution and interaction of damage modes in fabric-reinforced composites under dynamic flexural loading. Composites Science and Technology. 2014;92:55-63.

[5] Chen. X, Zhao. W, Zhao. XL, Xu JZ. Preliminary failure investigation of a $52.3 \mathrm{~m}$ glass/epoxy composite wind turbine blade. Engineering Failure Analysis. 2014;44:345-50.

[6] Future perspectives for design and testing of wind turbine blades, Awhite paper on a rational approach to

defects and damage tolerance, Det Norske Veritas AS, Report no WTDK6022,2008.(http://www.dnv.us/binaries/damage_tolerance-white_paper 2008 tcm153-295072.pdf). 2008.

[7] Aktaş M, Ersen Balcıŏlu H, Aktaş A, Türker E, Emin Deniz M. Impact and post impact behavior of layer fabric composites. Composite Structures. 2012;94:2809-18.

[8] Iannucci L, Willows M. An energy based damage mechanics approach to modelling impact onto woven composite materials--Part I: Numerical models. Composites Part A: Applied Science and Manufacturing. 2006;37(11):204156.

[9] Kim JK, Sham ML. Impact and delamination failure of woven-fabric composites. Composites Science and Technology. 2000;60(5):745-61.

[10] Naik N, Chandra Sekher Y, Meduri S. Damage in woven-fabric composites subjected to low-velocity impact. Composites Science and Technology. 2000;60(5):731-44.

[11] Silberschmidt VV, Casas-Rodriguez JP, Ashcroft IA. Impact fatigue of adhesive joints. Key Engineering Materials. 2009;399:71-8.

[12] Casas-Rodriguez J, Ashcroft IA, Silberschmidt VV. Damage in adhesively bonded CFRP joints: Sinusoidal and impact-fatigue. Composites Science and Technology. 2008;68(13):2663-70.

[13] Ullah H, Harland AR, Silberschmidt VV. Damage modelling in wovenfabric CFRP laminates under large-deflection bending. Computational Materials Science. 2012;64:130-5.

[14] Turon A, Davila CG, Camanho PP, Costa J. An engineering solution for mesh size effects in the simulation of delamination using cohesive zone models. Engineering Fracture Mechanics. 2007;74(10):1665-82.

[15] Benzeggagh ML, Kenane M. Measurement of mixed-mode delamination fracture toughness of unidirectional glass/epoxy composites with mixed-mode bending apparatus. Composites Science and Technology. 1996;56(4):439-49.

[16] Daudeville L, Allix O, Ladeveze P. Delamination analysis by damage mechanics: some applications. Composites Engineering. 1995;5(1):17-24. 